\title{
Quantitative measurement of fertilizer uptake by crops
}

\author{
H. Broeshart
}

Joint FAO/IAEA Division of Atomic Energy in Food and

Agriculture, International Atomic Energy Agency, Laboratory Seibersdorf, Vienna, Austria

\section{Introduction}

Fertilizers have to be applied regularly to crops to maintain a high production level. This is particularly true for those areas of the world where highly productive crop varieties have been obtained as a result of breeding and where the cost of fertilizer is small in comparison with the overall production cost and value of the crop. This situation does not prevail in so-called developing countries where high-yielding crop varieties are normally not available and where the cost of fertilizer is a large proportion of the value of the crop yield.

With regard to the nature of fertilizer applications, it is well known that at least the major plant nutrients, $\mathrm{N}, \mathrm{P}$ and $\mathrm{K}$, have to be applied regularly to compensate for the plant nutrients that are removed from the soil by the harvest, and it is obvious that other elements such as $\mathrm{Mg}, \mathrm{Ca}, \mathrm{S}$ and the micro-elements may become deficient if they are only exported from the soil with the harvest and never return to the soil in the form of fertilizers.

The purpose of applying fertilizers is to supply the crop with essential plant nutrients. As a consequence, fertilizer applications should be made in such a way that

- maximum uptake by the crop takes place

- the availability of fertilizer nutrient is not reduced due to unfavourable soil-fertilizer interactions

- harmful contamination of the environment, in particular of ground-water, with fertilizer nutrients is avoided.

In practice, all of the above objectives are obtained by proper fertilizer placing, correct timing of the application and applying the fertilizer in an appropriate physical and chemical form.

The best combination of placing, timing and nature of fertilizer can be established for each crop by carrying out properly designed field experiments under a wide variety of soil and climatic conditions. When these experiments have identical design and layout, it is possible to determine what generalizations can be made with respect to placing, timing and nature of fertilizer that result in the highest fertilizer uptake by the crop.

The quantitative direct measurement of fertilizer uptake can essentially be done in two ways:

- as the difference in the amount of nutrient in the crop growing in the presence and absence of fertilizer;

- by means of isotope techniques and the use of isotopically labelled fertilizers.

Finally, it should be mentioned that still large numbers of field experiments are being carried out where an indirect assessment is made of fertilizer uptake by simply comparing crop yields.

It is the purpose of this paper to evaluate the methods mentioned above for quantitative 
assessment of fertilizer uptake based on the results of 12 years of laboratory, greenhouse and field experiments which were carried out within the framework of an international co-operative programme of the Joint FAO/IAEA Division of Atomic Energy in Food and Agriculture in Vienna, Austria (Anon., 1970a, 1970b, 1974a, 1974b).

\section{The indirect method for measuring fertilizer uptake}

A comparison of methods of fertilizer application with a view to finding out which placement, timing or nature of fertilizer should be recommended for agricultural practice is frequently made on the basis of crop yields. It is often stated that it is finally the 'yield' that matters and the knowledge of how much fertilizer is taken up by the crop is of no interest to the farmer. If the application of two different kinds of nitrogen fertilizer or banding or broadcasting of phosphorus does not result in differences in crop yields, the conclusion is drawn that the two sources of nitrogen and the two methods of phosphate application are apparently identical.

This reasoning is entirely misleading. It is true that a farmer is interested in 'yield'; he is however at the same time interested in obtaining this yield at the lowest cost, i.e. with a minimum amount of fertilizer. Ideally this would be a fertilizer application practice whereby all the fertilizer applied is taken up by the crop and ensures maximum yield. In addition, we are now well aware of the hazards that are involved in a continuous over-supply of chemicals to our environment.

It is obvious that crop yield is affected by many other environment factors besides fertilization. But even if experimental conditions could be chosen such that crop yield would be a function of the amount of nutrient supplied by the fertilizer, it would not be possible to quantitatively assess how much better fertilizer I would be in comparison with fertilizers II or III. This may be illustrated by Fig. 1 (Fried and Broeshart, 1967) where crop yie!d is given as a function of the rate of nutrient supply from fertilizer. Points I, II and III on the abscissa may, for example, represent the rate of supply corresponding with different methods of placement or different kinds of nitrogen fertilizer.

It is clear that the supply corresponding with Treatment III is $50 \%$ more than from Treatment II and three times as much as Treatment I. Still it would hardly be possible to quantitatively measure yield differences between Treatment III and II and impossible to equate Treatment III and II to treatment I. Experimentally it is difficult to obtain

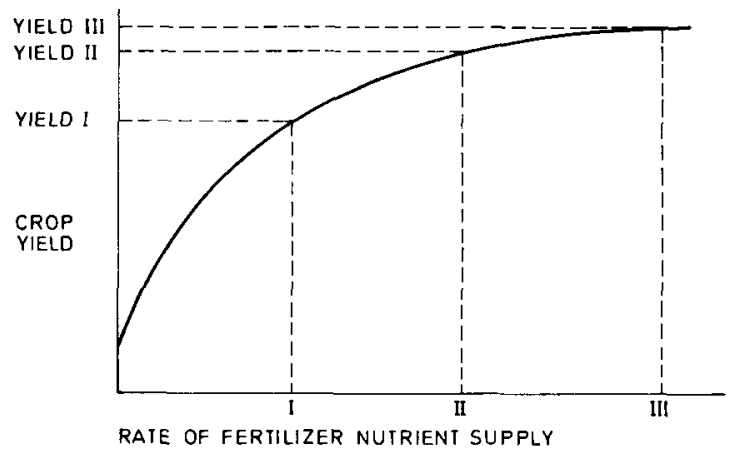

Fig. 1. Crop yield as a function of rate of fertilizer nutrient supply. 
yield curves under conditions where the nutrient is not extremely deficient. Therefore there is little justification for using crop yield as an indirect measure for fertilizer uptake, particularly as one can directly measure fertilizer uptake, for instance by means of isotope techniques.

\section{The direct method for measuring fertilizer uptake}

In principle two methods of approach are available. Most commonly, fertilizer uptake by a crop is measured as the difference in nutrient yield of a crop growing in the presence and absence of fertilizer. The crop which is growing in the absence of fertilizer essentially serves as an estimate of available soil nutrient. The fertilized plot serves to measure soil plus fertilizer nutrient. When the assumption is made that the amount of soil nutrient taken up by the crop is independent of the amount of fertilizer applied, the amount of of nutrient taken up from the fertilizer can be obtained by subtraction.

The other approach involves the use of isotopically labelled fertilizer and does not require unfertilized control plots. If the specific activity of the nutrient in the fertilizer is $S_{\mathrm{f}}$, the amount supplied $\mathrm{B} \mathrm{kg} / \mathrm{ha}$ and the specific activity found in the plant material $S_{p}$, the amount of element in the crop derived from fertilizer $F_{p}=\left(S_{p} / S_{f}\right) \times B ~ k g / h a$.

No assumptions have to be made other than that label and carrier element (i.e. ${ }^{31} \mathrm{P},{ }^{32} \mathrm{P}$ and ${ }^{33} \mathrm{P}$ or ${ }^{14} \mathrm{~N}{ }^{15} \mathrm{~N}$ ) behave chemically and physically identically in the soil. It should be stressed that no assumptions have to be made with respect to the behaviour of fertilizer in soil, i.e. whether part of the fertilizer becomes involved in chemical reactions, biological processes or ion exchange. An objection to the use of isotopically labelled nitrogen or phosphate fertilizer has often been raised on the grounds that it makes no sense to measure fertilizer uptake because, due to isotope dilution in the soil, the fertilizer soon loses its identity and becomes part of the pool of nutrient in the soil. One may argue about the processes involved and the time required for the fertilizer to 'lose' its identity, but this does not affect the conclusion as to how much of the applied fertilizer ended up in the crop. If a plant is growing on a culture solution containing, for instance, nitrogen as nitrate, and ${ }^{15} \mathrm{~N}$-labelled nitrate is added to the solution, complete isotopic equilibrium will soon be established. Still, after measuring the percentage of ${ }^{15} \mathrm{~N}$ excess in the crop, one can calculate exactly the amount of nitrate in the plant that was derived from the addition of ${ }^{15} \mathrm{~N}$ labelled nitrate to the culture solution.

\section{Comparison of 'difference' and 'isotope' methods}

By means of isotope techniques it is possible to check whether the assumption is correct that the amount of element taken up from the soil is independent of rate of fertilizer nutrient supply. Table 1 (Aleksic et al., 1968) shows that in the case of nine different soils which received applications of $\left(\mathrm{NH}_{4}\right)_{2} \mathrm{SO}_{4}$ ranging from $0-200 \mathrm{~kg} \mathrm{~N} / \mathrm{ha}$, the amount of nitrogen derived from soil in the presence of nitrogen fertilizer greatly exceeds the amount of nitrogen taken up from non fertilized control. It is evident that with increasing rate of $\mathrm{N}$ application, the dry matter production and total $\mathrm{N}$ in the crop increases.

The increased $\mathrm{N}$ uptake by the crop induced by the application of $\mathrm{N}$ fertilizer is apparently not due to an increased uptake from the fertilizer alone but also to a simultaneous increase in uptake from soil $\mathrm{N}$.

The 'apparent' effect of fertilizer $\mathrm{N}$ on the availability of soil $\mathrm{N}$ has received consid- 
Table 1. Effect of rate of application of $\left(\mathrm{NH}_{4}\right)_{2} \mathrm{SO}_{4}$ on the supply of nitrogen from the soil (Aleksic et al., 1968).

\begin{tabular}{|c|c|c|c|c|c|c|}
\hline $\begin{array}{l}\text { Soil } \\
\text { origin }\end{array}$ & $\begin{array}{l}\text { Rate of } \\
\text { nitrogen } \\
\text { application } \\
\text { (kg N/ha) }\end{array}$ & $\begin{array}{l}\text { Dry matter } \\
\text { production } \\
\text { (g/pot) }\end{array}$ & $\begin{array}{l}\text { Total } \mathrm{N} \\
\text { in shoots } \\
(\mathrm{mg} / \mathrm{pot})\end{array}$ & $\begin{array}{l}\mathrm{N} \text { derived } \\
\text { from } \\
\text { fertilizer } \\
(\mathrm{mg} / \text { pot })\end{array}$ & $\begin{array}{l}N \text { derived } \\
\text { from } \\
\text { soil } \\
\text { (mg/pot) }\end{array}$ & $\begin{array}{l}\mathrm{AN}_{\mathrm{N}} \\
\text { value } \\
(\mathrm{mg} / \mathrm{kg})\end{array}$ \\
\hline Brazil & $\begin{array}{r}0 \\
50 \\
100 \\
200\end{array}$ & $\begin{array}{l}0.42 \\
2.08 \\
2.09 \\
3.06\end{array}$ & $\begin{array}{r}13 \\
47 \\
58 \\
116\end{array}$ & $\begin{array}{l}- \\
14 \\
27 \\
72\end{array}$ & $\begin{array}{l}13 \\
33 \\
31 \\
44\end{array}$ & $\begin{array}{l}- \\
61 \\
55 \\
61\end{array}$ \\
\hline Argentina & $\begin{array}{r}0 \\
50 \\
100 \\
200\end{array}$ & $\begin{array}{l}2.38 \\
4.15 \\
4.54 \\
5.76\end{array}$ & $\begin{array}{r}33 \\
60 \\
83 \\
130\end{array}$ & $\begin{array}{l}- \\
11 \\
27 \\
67\end{array}$ & $\begin{array}{l}33 \\
49 \\
56 \\
63\end{array}$ & $\begin{array}{r}- \\
112 \\
104 \\
95\end{array}$ \\
\hline Romania & $\begin{array}{r}0 \\
50 \\
100 \\
200\end{array}$ & $\begin{array}{l}0.98 \\
1.88 \\
1.60 \\
2.02\end{array}$ & $\begin{array}{l}31 \\
60 \\
53 \\
74\end{array}$ & $\begin{array}{r}- \\
8 \\
12 \\
28\end{array}$ & $\begin{array}{l}31 \\
52 \\
41 \\
46\end{array}$ & $\begin{array}{r}- \\
159 \\
162 \\
163\end{array}$ \\
\hline Egypt & $\begin{array}{r}0 \\
50 \\
100 \\
200\end{array}$ & $\begin{array}{l}0.78 \\
1.78 \\
1.44 \\
1.60\end{array}$ & $\begin{array}{l}13 \\
27 \\
32 \\
51\end{array}$ & $\begin{array}{r}- \\
4 \\
9 \\
24\end{array}$ & $\begin{array}{l}13 \\
23 \\
23 \\
27\end{array}$ & $\begin{array}{r}- \\
123 \\
122 \\
116\end{array}$ \\
\hline Colombia & $\begin{array}{r}0 \\
50 \\
100 \\
200\end{array}$ & $\begin{array}{l}2.05 \\
3.38 \\
4.27 \\
4.53\end{array}$ & $\begin{array}{r}30 \\
48 \\
84 \\
119\end{array}$ & $\begin{array}{l}- \\
13 \\
37 \\
72\end{array}$ & $\begin{array}{l}30 \\
35 \\
47 \\
47\end{array}$ & $\begin{array}{l}- \\
69 \\
65 \\
65\end{array}$ \\
\hline Austria & $\begin{array}{r}0 \\
50 \\
100 \\
200\end{array}$ & $\begin{array}{l}2.03 \\
2.75 \\
2.08 \\
1.74\end{array}$ & $\begin{array}{l}39 \\
63 \\
70 \\
64\end{array}$ & $\begin{array}{l}- \\
15 \\
25 \\
34\end{array}$ & $\begin{array}{l}39 \\
48 \\
45 \\
30\end{array}$ & $\begin{array}{r}- \\
77 \\
91 \\
85\end{array}$ \\
\hline Peru & $\begin{array}{r}0 \\
50 \\
100 \\
200\end{array}$ & $\begin{array}{l}0.34 \\
0.75 \\
0.78 \\
0.53\end{array}$ & $\begin{array}{l}12 \\
27 \\
25 \\
19\end{array}$ & $\begin{array}{r}- \\
4 \\
7 \\
10\end{array}$ & $\begin{array}{r}12 \\
23 \\
18 \\
9\end{array}$ & $\begin{array}{r}- \\
114 \\
123 \\
106\end{array}$ \\
\hline Mexico & $\begin{array}{r}0 \\
50 \\
100 \\
200\end{array}$ & $\begin{array}{l}1.31 \\
2.48 \\
3.02 \\
2.36\end{array}$ & $\begin{array}{l}13 \\
34 \\
60 \\
79\end{array}$ & $\begin{array}{r}- \\
12 \\
32 \\
54\end{array}$ & $\begin{array}{l}13 \\
22 \\
28 \\
25\end{array}$ & $\begin{array}{l}- \\
47 \\
45 \\
46\end{array}$ \\
\hline Yugoslavia & $\begin{array}{r}0 \\
50 \\
100 \\
200\end{array}$ & $\begin{array}{l}1.05 \\
1.63 \\
2.97 \\
3.19\end{array}$ & $\begin{array}{l}11 \\
26 \\
53 \\
93\end{array}$ & $\begin{array}{r}- \\
9 \\
27 \\
64\end{array}$ & $\begin{array}{l}11 \\
17 \\
26 \\
29\end{array}$ & $\begin{array}{l}- \\
46 \\
49 \\
47\end{array}$ \\
\hline
\end{tabular}

erable attention and has been called 'priming'. This 'priming' is often attributed to an effect of fertilizer on the rate of supply of soil nutrient through physico-chemical and/or microbiological processes taking place in the soil. When the assumption is made that a plant confronted with two sources of nutrient will take up those nutrients in amounts proportional to the availability of the nutrient in the two sources, the soil supply of $N$ can be calculated (Fried \& Dean, 1950). In other words, $\frac{\text { total } N \text { in crop }}{\text { total } N \text { from fertilizer }+ \text { soil supply }}=\frac{\text { fertilizer } N \text { in crop }}{\text { fertilizer } N \text { supply }}=\frac{\text { soil } N \text { in crop }}{\text { soil } N \text { supply }\left(=A_{N}\right)}$, 
in which the supply (availability) of total $\mathrm{N}$, soil $\mathrm{N}$ and fertilizer $\mathrm{N}$ is expressed in fertilizer equivalents. It can easily be seen from the data in Table 1, that the availability of soil $\mathrm{N}$ expressed in $\left(\mathrm{NH}_{4}\right)_{2} \mathrm{SO}_{4}$ equivalents $\left(\mathrm{A}_{\mathrm{N}}\right.$ values) is not affected by the rate of fertilizer $\mathrm{N}$ application.

However as a result of nitrogen fertilization, crops will take up more nitrogen from both soil and fertilizer because of better growth and higher dry matter production. Although there may well be effects of addition of fertilizer on the rate of soil supply of nutrients, the data in Table 1 illustrate the close relationship between dry matter production and 'priming effect'. The assumption on which the 'difference' method is based, i.e. that a crop growing on a non fertilized control plot may serve as an estimate for the soil nutrient supply in the presence of $\mathbf{N}$ fertilizer, is incorrect.

Whenever possible, fertilizer uptake should therefore be measured by using isotopically labelled fertilizer.

\section{Essential features of fertilizer uptake studies with isotopically labelled fertilizer}

Isotope labelling of fertilizer. For field experimentation, essentially only a limited number of isotopes are available. ${ }^{32} \mathrm{P}$ - and ${ }^{33} \mathrm{P}$-labelled phosphates as well as ${ }^{15} \mathrm{~N}$-labelled nitrogen fertilizer are most commonly used.

When it is necessary to evaluate phosphate fertilizer uptake in the final harvest of a crop with a growing period of 3-4 months, ${ }^{33} \mathrm{P}$ with its half-line of 28 days should be used. 32P has a half-line of only 14 days and can only be used if the time between application and isotopic assay of the plant samples in the laboratory is less than about 5-6 half-lives, i.e. $21 / 2-3$ months. Although ${ }^{33 P}$ is much more expensive that ${ }^{32} \mathrm{P}$, it can easily be seen that the relative difference in cost between ${ }^{33} \mathrm{P}$ and ${ }^{32} \mathrm{P}$ becomes increasingly less, the longer the time between fertilizer application and isotope analysis. For instance, for measurement of the same amount of activity after 3 months, one would require approximately eight times as much ${ }^{32} \mathrm{P}$ as ${ }^{33} \mathrm{P}$ in the initial phosphate application.

In the case of nitrogen, only the relatively expensive stable isotope ${ }^{15} \mathrm{~N}$ can be used for fertilizer studies. However, it is a lucky circumstance that during a growing season apparently very small quantities of fertilizer $\mathrm{N}$ accumulate in the organic matter fraction of the soil.

Because of the insignificant isotopic dilution of nitrogen fertilizer in soil, fertilizer enrichment need only be of the order of $1 \% 15 \mathrm{~N}$ atom excess for rates of application of $80-100 \mathrm{~kg} \mathrm{~N} / \mathrm{ha}$. During the past 10 years the price of ${ }^{15} \mathrm{~N}$ has decreased drastically because of the rapidly growing demand and because of the fact that relatively cheap emission spectrometers are now available for the determination of ${ }^{15} \mathrm{~N}$ abundance.

Mass spectrometry requires a high initial investment and the continuous presence of highly specialized staff.

Fig. 2 has been prepared to illustrate the amounts of ${ }^{15} \mathrm{~N}$ required for field experiments (Fried et al., 1966). It should be stressed that it is not necessary to apply ${ }^{15} \mathrm{~N}$ - or ${ }^{32} \mathrm{P}\left({ }^{33} \mathrm{P}\right)$ labelled fertilizers to entire field plots. One to three rows about $2 \mathrm{~m}$ length are usually adequate and the remainder of the plot rows may receive ordinary fertilizer of identical chemical and physical nature as the labelled material.

A final remark should be made with respect to the labelling of different kinds of fertilizer, in particular for the comparison of fertilizer uptake from different sources. It is essential that the manufacture of labelled fertilizers is identical to the manufacture of ordinary fertilizer.

It is not possible to label ordinary superphosphate by just adding a ${ }^{32} \mathrm{P}-$ labelled solution 


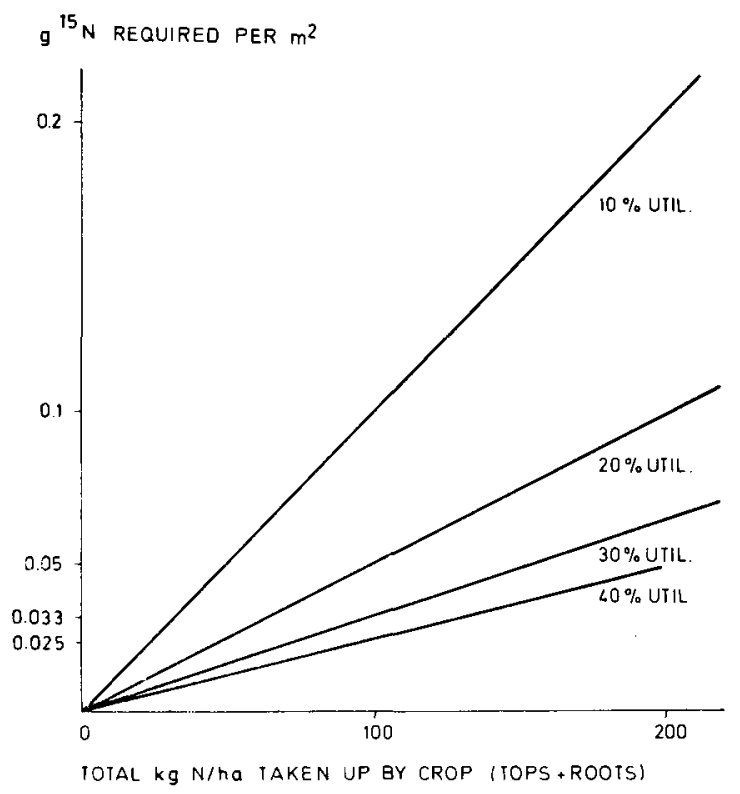

Fig. 2. The amount of ${ }^{15} \mathrm{~N}$ required for field experiments as a function of the predicted total nitrogen uptake by the crop and percentage of utilization of the fertilizer applied.

to the fertilizer because the product will not be homogeniously labelled and moreover will have different chemical characteristics as compared with the normal fertilizer.

Rate of application of fertilizer. For the comparison of placement, timing or nature of the fertilizer it is sufficient to use one rate of application. The inclusion of several rates of labelled fertilizer is usually not necessary. Once the fraction in the plant derived from fertilizer $F_{1}$ is known for a rate of application $B_{1} \mathrm{~kg} / \mathrm{ha}$, the fraction $F_{2}$ that would have been found for rate of application $B_{2}$ can easily be estimated. Since the amount of available nutrient $A$ in the soil is not affected by the fertilizer applications $B_{1}$ and $B_{2}$ (see Table 1 ), it is evident that $A=B_{1} \frac{\left(1-F_{1}\right)}{F_{1}}=B_{2} \frac{\left(1-F_{2}\right)}{F_{2}} . F_{2}$ is the only unknown in this equation and can be calculated.

There may be situations where during the experimental period the nature of the soil and/or fertilizer supply drastically change. In that case experiments including several rates of application may be used to quantify this change. As an example may serve the application of nitrogen fertilizer to a legume crop which obtains part of its nitrogen supply from symbiotic fixation. Increasing rates of applications of nitrogen fertilizer may interfere with the symbiotic fixation process.

Measurement of fertilizer uptake in presence and absence of plant-fertilizer interactions. Timing and placement may be studied in the presence and absence of effects of the treatments on plant development, root distribution and crop yield. Crop-fertilizer interactions may be highly important in respect of potential crop yield. For instance if one were tot apply $90 \mathrm{~kg} / \mathrm{ha}$ of ${ }^{15} \mathrm{~N}$-labelled fertilizer at one of three different times during crop development, i.e. $T_{1}, T_{2}$ and $T_{3}$, one might expect that certain crops would develop 
Table 2. Design of field experiments to study fertilizer uptake in presence or absence of fertilizer-plant interactions.

\begin{tabular}{|c|c|c|c|c|c|c|}
\hline \multirow[t]{2}{*}{ Treatment } & \multicolumn{3}{|c|}{$\begin{array}{l}\text { Section } \mathbf{I} \\
\text { (with plant } \times \mathrm{T} \text { interaction) }\end{array}$} & \multicolumn{3}{|c|}{$\begin{array}{l}\text { Section II } \\
\text { (without plant } \times \mathrm{T} \text { interaction) }\end{array}$} \\
\hline & $\overline{T_{1}}$ & $\mathrm{~T}_{2}$ & $\mathrm{~T}_{3}$ & $\overline{\mathbf{T}_{1}}$ & $\mathrm{~T}_{2}$ & $\mathrm{~T}_{3}$ \\
\hline 1 & $90^{*}$ & - & - & $30 *$ & 30 & 30 \\
\hline 2 & - & $90^{*}$ & - & 30 & $30^{*}$ & 30 \\
\hline 3 & - & - & $90^{*}$ & 30 & 30 & $30 *$ \\
\hline
\end{tabular}

* Application with labelled fertilizer.

well in the case of $T_{1}$ and would have a better developed root system at time $T_{2}$ than the plants receiving their first fertilizer application at $T_{2}$ or $T_{3}$. Other crops would utilize most of their nitrogen at $T_{3}$, for instance during grain production. Any comparison of the effect of timing would therefore be confounded with a treatment $\times$ plant interaction.

If, on the other hand, the plants were to receive $30 \mathrm{~kg} \mathrm{~N} / \mathrm{ha}$ at all timing treatments and only one timing treatment were to consist of labelled fertilizer, the effect of timing would be measured in the absence of any interaction effect (see Table 2).

As opposed to Section $I$ in the table where treatment and plant response are confounded, Section II of the table illustrates the situation where the labelled fertilizer is always applied under identical crop conditions. The sum of treatments $T_{1}+T_{2}+T_{3}$ would measure the total fertilizer uptake in the absence of any crop-fertilizer interaction effect (Fried \& Soper, 1974).

The above type of design can equally well be used for fertilizer placement studies. This means that in one plot one would apply equal quantities of fertilizer, for instance broadcast, in a band at $5 \mathrm{~cm}$ and in a band at $10 \mathrm{~cm}$ depth and would only label one of the placements.

Measurement of symbiotic $N$ fixation by legume crops. Most legume crops essentially need not receive nitrogen fertilizer since under optimal conditions of symbiotic nitrogen fixation the amounts of nitrogen supplied to the crop are usually adequate to ensure maximum crop production. Only when the yield is high, as is the case with soybeans, it may be necessary to apply additional fertilizer nitrogen. Many factors such as soil $\mathbf{N}$ supply, nature of $\mathrm{P}$ fertilization, moisture supply, $\mathrm{pH}$ and effectiveness of the rhizobium inocculant may affect symbiotic $\mathrm{N}$ fixation.

By means of application of small amounts of ${ }^{15} \mathrm{~N}$-labelled nitrogen fertilizer it is possible to estimate the effect of the above mentioned kinds of treatments on the amount of nitrogen which a crop can symbiotically fix (Fried \& Broeshart, 1974). The rate of ${ }^{15} \mathrm{~N}$-labelled nitrogen fertilizer will generally not exceed $30 \mathrm{~kg} \mathrm{~N} / \mathrm{ha}$, otherwise the $\mathrm{N}$ fertilizer itself may have an effect on the rate at which symbiotic $\mathrm{N}$ fixation is taking place.

A nodulating legume crop is confronted with three sources of nitrogen, $\mathbf{A}_{\text {soil, }} \mathbf{A}_{\text {air }}$

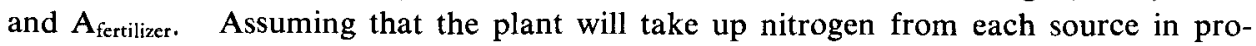
portion to the relative $\mathrm{N}$ availability in each source, it follows that

$\frac{F_{\text {fert }}}{A_{\text {fert }}}=\frac{F_{\text {soil }}}{A_{\text {soil }}} \frac{F_{\text {air }}}{A_{\text {symb. }}}$ 
Table 3. Calculation of amount of $\mathrm{N}$ symbiotically fixed by soybeans, with ' $\mathrm{A}$ ' values and utilisation (\%) of applied fertilizer.

\begin{tabular}{lccc}
\hline & Nodulating & Non-nodulating & $\begin{array}{c}\text { Difference } \\
\text { 'A' symb. }\end{array}$ \\
Fertilizer applied $(\mathrm{kg} / \mathrm{ha})$ & 30 & 100 & \\
$\% \mathrm{~N}$ derived from fertilizer & 3.4 & 16.5 & 346 \\
'A' value in fertilizer units & 852 & 506 & \\
Fertilizer taken up by nodulating beans & 10.7 & \\
$(\mathrm{~kg} / \mathrm{ha})$ & 35.7 & \\
$\%$ utilisation $(10.7 / 30 \times 100)$ & 124 & \\
Symbiotically fixed $\mathrm{N}(346 \times 35.7 \mathrm{~kg} / \mathrm{ha})$ & & \\
\hline
\end{tabular}

$F$ denotes the fraction in the plant derived from a particular source and $A$ the available amounts of nitrogen in each source, expressed in fertilizer equivalents. From the analysis of plant material it will however only be possible to determine $F_{\text {soll }}+F_{\text {symb. }}$ and consequently only the sum of $\mathbf{A}_{\text {soil }}+\mathbf{A}_{\text {symb. }}$ can be calculated. If it is assumed that a nonnodulating crop is confronted with the same source of soil nitrogen supply as the legume crop, it is possible to make an independent estimate of $A_{\text {soil }}$. This can be done by inclusion of a treatment whereby a non-nodulating crop is given an application of the same

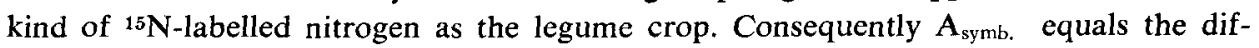
ference $A_{\text {soil }}+$ symb. $-A_{\text {soil }}$. The actual amount of symbiotically fixed $\mathbf{N}$, expressed in

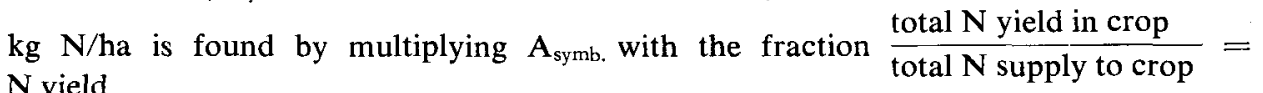
$\frac{N \text { yield }}{A_{\text {soil }}+\text { symb. }}+A_{\text {fert. }}$. It is obvious that this fraction is identical to $\frac{\text { total fertilizer nitrogen in crop }}{\text { amount of fertilizer } N \text { applied }}=\frac{\% \mathrm{~N} \times \text { dry matter yield } \times \mathrm{F}_{\text {fer: }}}{A_{\text {fert }}}$

Table 3 gives an example of such an experiment, with nodulating and non-nodulating soy-beans.

Fertilizer uptake by tree crops. The quantitative assessment of fertilizer uptake by tree crops is complicated by the fact that it is not possible to obtain an estimate of $F_{1}$ the fraction in the tree derived from fertilizer. The labelled fertilizer, after having been taken up, is translocated to different degrees to various parts of the tree. In some trees, such as cocoa, oil palm or coconut palm, translocation of $\mathbf{P}$ or $\mathbf{N}$ from roots to leaves takes place rapidly and leaf samples of comparative age and morphological position can be taken to assess differences in fertilizer uptake corresponding with the nature of the application or source. Other tree species, such as citrus, coffee or apple trees do not exhibit rapid translocation of $\mathrm{N}$ and $\mathrm{P}$ and consequently when one side of the tree receives a higher supply of fertilizcr, due to placement or irregular lateral root patterns, the leaves of such trees will always show a higher isotope content when they have been taken from the side where the fertilizer supply was higher.

In order to at least have a measurement of isotope in the leaves that is proportional to the fraction of element in the tree that was derived from fertilizer, fertilizer application and leaf sampling techniques have to be rigorously standardized. Due to the fact that many trees have a very irregular lateral root distribution pattern, fertilizer treatments are usually made in concentric rings at various distances and depths. Because of the great 
Table 4. Comparison of single and double labelling techniques for root studies with trees (Betula) (Means of ratios and activities of 4 replications.)

\begin{tabular}{|c|c|c|c|c|}
\hline \multirow{2}{*}{$\begin{array}{l}\text { Depth of } \\
\text { s2P* injections } \\
(\mathrm{cm})\end{array}$} & \multicolumn{2}{|l|}{ Leaf ${ }^{32} \mathrm{P}^{*} / 3 \mathrm{~s} \mathrm{P}$ ratio } & \multicolumn{2}{|c|}{ Leaf ${ }^{32} \mathbf{P}$ in $\mathrm{cpm} / \mathrm{mg}$ dry matter } \\
\hline & $12^{32} \mathrm{P}$ injections & $24{ }^{32} P$ injections & $12{ }^{32} \mathrm{P}$ injections & $24{ }^{22} \mathrm{P}$ injections \\
\hline 10 & 1.0 & 2.0 & 162 & 192 \\
\hline 20 & 0.86 & 1.7 & 178 & 112 \\
\hline \multirow[t]{2}{*}{30} & 0.9 & 1.4 & 94 & 407 \\
\hline & \multicolumn{2}{|c|}{$\begin{array}{l}\text { LSD at } \mathrm{P}=0.05=0.84 \\
\sigma=49 \%\end{array}$} & \multicolumn{2}{|c|}{$\begin{array}{l}\text { no significant difference } \\
\sigma=100 \%\end{array}$} \\
\hline
\end{tabular}

* 12 injections of ${ }^{33} \mathrm{P}$ were made in a ring at a depth of $10 \mathrm{~cm}$ in addition to ${ }^{32 P}$ injections.

variability in fertilizer uptake amoung trees, even when they are growing in regular patterns, such as in plantations, a large number of trees should be included in each fertilizer treatment. The cost involved in such experiments is very high because of the large quantities of labelled fertilized that are required. In practice, one does not apply labelled fertilizers but injects relatively small amounts of labelled solutions in concentric rings at various distances and depths to 'map' the active root pattern distribution.

Double labelling techniques, with ${ }^{32} \mathrm{P}$ - and ${ }^{33 \mathrm{P}}$-labelled phosphate solutions that are injected at different depths, enable the determination of the ratio of for instance two depths or two distances of placing on the same tree and tremendously reduce the variation between trees in the assessment of relative effectiveness of two methods of placing (Broeshart \& Nethsinghe, 1972). Similarly, two different kinds of phosphate fertilizers can be compared, if one source is labelled with ${ }^{32} \mathrm{P}$ and the other with ${ }^{33} \mathrm{P}$ and both are applied in identical locations. The ratio of the ${ }^{32} \mathrm{P} / 33 \mathrm{P}$ activities in the leaves directly reflects the ratio of availabilities of $\mathbf{P}$ in the two fertilizers. A comparison of single and double labelling with ${ }^{32} \mathrm{P}$ and ${ }^{33} \mathrm{P}$ has been given in Table 4.

\section{Future development}

The increasing level at which ground water is becoming polluted with $\mathrm{N}, \mathrm{P}$ and other elements forces us to investigate to what extent the use of fertilizer has contributed to this pollution. It is not the purpose of this paper to discuss the various aspects of the fate of fertilizer that is not taken up by crops. The opinions among those concerned with the evaluation of fertilizer practices is conflicting. It may however be taken for granted that increased attention has to be devoted to this aspect of fertilization (Fried \& Broeshart, 1974). We have never succeeded in having all the fertilizer that is applied to the soil taken up by the crop. It seems likely, however, that in the near future the efficient use of fertilizer by crops will only be one part of the more complex problem of what the fate of fertilizer is in the entire soil-plant system.

\section{References}

Aleksic, Z., H. Broeshart \& V. Middelboe, 1968. The effect of nitrogen fertilization on the release of soil nitrogen. Pl. Soil 29 3: 474.

Anonymous, 1970a. Rice fertilization. International Atomic Energy Agency, Joint FAO/IAEA Division of Atomic Energy in Food and Agriculture, Vienna. Technical Reports Series No 108. 
Anonymous, 1970b. Fertilizer management practices for maize. International Atomic Energy Agency, Joint FAO/IAEA Division of Atomic Energy in Agriculture, Vienna. Technical Reports Series No 121.

Anonymous, 1974a. Isotope studies on wheat fertilization. International Atomic Energy Agency, Joint FAO/IAEA Division of Atomic Energy in Agriculture, Vienna. Technical Reports Series (in press).

Anonymous, 1974b. Root activity patterns of tree crops. International Atomic Energy Agency, Joint FAO/IAEA Division of Atomic Energy in Agriculture, Vienna. Technical Reports Series (in press).

Broeshart, H. \& D. A. Nethsinghe, 1972. Studies on the pattern of root activity of tree crops using isotope techniques. In: Isotopes and radiation in soil-plant relationships including forestry, International Atomic Agency, Vienna, p. 453-463.

Fried, M. \& H. Broeshart, 1967. The soil plant system in relation to inorganic nitrition. Academic Press, New York.

Fried, M. \& H. Broeshart, 1974. Essential features of the soil-plant system. Semaine d'Etude Sol et Fertilisation, 3-7 September 1973. Bull. Rech. Agron. Gembloux.

Fried, M. \& H. Broeshart, 1974. An independent measurement of amount of nitrogen fixed by a legume crop. (In press.)

Fried, M., H. Broeshart, C. M. Cho \& A. C. Caldwell, 1966. Field experiments with N-15 on efficiency of fertilizer utilization for maize. Annual Meeting of the American Society of Agronomy, Stillwater, Oklahoma.

Fried, M. \& L. A. Dean, 1950. A concept concerning the measurement of avalable soil nutrient. Res. Rep. Div. Soil Mangmt Irrig. U.S: Dep. Agric. 197.

Fried, M. \& R. Soper, 1974. The one treatment fertilizer experiment. (In press.) 